DOI: 10.18027/2224-5057-2017-7-3s1-41-46

Цитирование: Солодкий В.А., Сотников В. М., Паньшин Г.А., Троценко С. Д., Харченко В. П. и др. Роль современных технологий послеоперационной лучевой терапии в комбинированном лечении немелкоклеточного рака легкого // Злокачественные опухоли. - 2017. - Т. 7. - № 3, спецвыпуск 1. - С. 41-46.

\title{
Роль современных технологий послеоперационной лучевой терапии в комбинированном лечении немелкоклеточного рака легкого
}

\author{
В. А. Солодкий, В. М. Сотников, Г. А. Паньшин, С.Д. Троценко, В.П. Харченко, В.Д. Чхиквадзе, Н. В. Нуднов, А. А. Моргунов \\ ФГБУ «Российский научный центр рентгенорадиологии» \\ Министерства здравоохранения Российской Федерации, г. Москва, Россия \\ Адрес для переписки: Троценко Сергей Дмитриевич, e-mail: trotsenkosd87@mail.ru
}

\section{Информация об авторах:}

Владимир А. Солодкий, д. м. н., профессор, академик РАН, директор ФГБУ «Российский научный центр рентгенорадиологии» МЗ РФ, e-mail: director@rncrr.ru

Владимир М. Сотников, д. м. н., проф., зав. лабораторией лучевой терапии научно-исследовательского отдела инновационных технологий радиотерапии и химиолучевого лечения злокачественных новообразований PHЦPP, e-mail: vmsotnikov@mail.ru

Георгий А. Паньшин, д. м. н., проф., руководитель отдела инновационных технологий радиотерапии и химиолучевого лечения злокачественных новообразований РНЦРP, e-mail: g.a.panshin@mail.ru

Сергей Д. Троценко, к. м. н., врач-радиолог отделения дистанционной лучевой терапии клиники радиотерапии РНЦРР, e-mail: trotsenkosd87@mail.ru

Владимир П. Харченко, д. м. н., профессор, академик РАН, научный руководитель ФГБУ «Российский научный центр рентгенорадиологии» МЗ РФ, e-mail: director@rncrr.ru

Владимир Д. Чхиквадзе, д. м. н., профессор, руководитель научно-исследовательского отдела хирургии и хирургических технологий в онкологии РНЦРP, e-mail: vdc@mail.ru

Николай В. Нуднов, д. м. н., профессор, зам директора ФГБУ «Российский научный центр рентгенорадиологии» МЗ РФ по научной работе, e-mail nudnov@rncrr.ru

Александр А. Моргунов, старший научный сотрудник организационного отдела ФГБУ РНЦРP, e-mail: al-morgunov@mail.ru

Лидирующие позиции рака легкого в структуре заболеваемости и смертности онкологических больных диктуют необходимость постоянного изучения новых методик и программ лечения данного заболевания [24]. При немелкоклеточном раке легкого (НМРЛ) используются все существующие методы лечения - хирургический, лучевой, лекарственный, и тактика лечения зависит от стадии заболевания и общего состояния пациента [1, 2, 3, 4, 11]. Однако вопрос персонализации программ комбинированного и комплексного лечения НМРЛ и оптимальной последовательности применения различных методов в рамках этих программ изучен недостаточно и продолжает обсуждаться. Общепризнано, что выполнение радикальной операции остается наиболее эффективным методом для пациентов с локальным и местнораспространенным НМРЛ. Однако, даже после радикальной операции частота локальных и регионарных рецидивов, а также отдаленных метастазов остается достаточно высокой (до $40 \%$ и до $67 \%$ соответственно) [36, 38, 20]. По ретроспективным данным, после хирургического лечения больных НМРЛ частота локорегионарных рецидивов составляет от 6-28\% для стадии pN0, от $18-49 \%$ для стадии $\mathrm{pN} 1$, и от $6-65 \%$ для стадии $\mathrm{pN} 2$ [25]. Следует отметить, что у радикально прооперированных пациентов с метастазами НМРЛ в медиастинальные лимфатические узлы (pN2) наблюдаются также наиболее низкие показатели 5-летней общей выживаемости 
Табл. 1. Ретроспективные исследования, оценивающие эффективность ПОЛТ при немелкоклеточном раке легкого

\begin{tabular}{|c|c|c|c|c|c|c|}
\hline Исследование & Стадии НМРЛ & Кол-во больных & СОД (Гр) & $\begin{array}{c}\text { Локальные } \\
\text { рецидивы }\end{array}$ & $\begin{array}{c}\text { Общая } \\
\text { выживаемость }\end{array}$ & $\begin{array}{c}\text { Период } \\
\text { наблюдения }\end{array}$ \\
\hline \multirow{2}{*}{ Astudillo, Connill, 1990г [14] } & \multirow{2}{*}{ IIIA } & 60 & - & $20 \%$ & $28 \%$ & \multirow{2}{*}{3 года } \\
\hline & & 86 & $45-50$ & $13 \%$ & $20 \%$ & \\
\hline \multirow{2}{*}{ Chung et al., 1982г [17] } & \multirow{2}{*}{ I-IIIA } & 68 & - & $32 \%$ & $28 \%$ & \multirow{2}{*}{3 года } \\
\hline & & 50 & 46 & $10 \%$ & $40 \%$ & \\
\hline \multirow{2}{*}{ Kirsh et al., 1982г [27] } & \multirow{2}{*}{ IIIA } & 20 & - & - & $0 \%$ & \multirow{2}{*}{5 лет } \\
\hline & & 110 & $50-60$ & - & $26 \%$ & \\
\hline \multirow{2}{*}{ Sawyer et al., 1997г [37] } & \multirow{2}{*}{ IIIA } & 136 & - & $60 \%$ & $22 \%$ & \multirow{2}{*}{4 года } \\
\hline & & 88 & $45-66$ & $17 \%$ & $43 \%$ & \\
\hline
\end{tabular}

(12-28\%) [7]. Поражение лимфатических узлов средостения считается одним из самых неблагоприятных прогностических факторов, так как данная группа пациентов обладает наиболее высоким риском развития как локорегионарных рецидивов, так и отдаленных метастазов [22]. А выживаемость больных НМРЛ со смешанным типом рецидива (локорегионарным + отдаленным метастазированием) достоверно меньше по сравнению с пациентами, у которых развились только отдаленные метастазы [42].

При хирургическом лечении ранних стадий НМРЛ (IA, IB, IIA, IIB) проблема локорегионарного контроля заболевания имеет самостоятельное клиническое значение, поскольку в структуре рецидивов данной когорты больных преобладают локорегионарные рецидивы [28, 30, 45]. Эти данные дают основание для включения в программу лечения адьювантной химиотерапии и послеоперационной лучевой терапии (ПОЛТ).

Результаты нескольких рандомизированных исследований и мета-анализов продемонстрировали, что проведение адьювантной химиотерапии на базе препаратов платины позволяет повысить показатели общей выживаемости больных НМРЛ [23, 19, 34, 13], однако не влияет на уровень локорегионарного контроля [43]. Таким образом, ПОЛТ остается практически единственным методом предупреждения как локальных, так и регионарных рецидивов у этой группы пациентов.

Первые статистически подтвержденные положительные результаты комбинированного лечения НМРЛ с послеоперационной лучевой терапией были опубликованы еще в 60-х годах прошлого века [9, 33], и уже в монографии Б.Е. Петерсона 1971 г. [5] отмечается возможность проведения послеоперационной лучевой терапии при выявлении метастазов в лимфатических узлах средостения. В последующие тридцать лет послеоперационная лучевая терапия НМРЛ продолжала исследоваться и применяться как в нашей стране, так и за рубежом [10], а результаты ретроспективных исследований за этот период времени продемонстрировали, что проведение ПОЛТ позволяет существенно снизить риск возникновения локорегионарных рецидивов на $25 \%-35 \%$ [14, 17, 27 , 37] (Табл. 1).
Полученные данные вызвали огромный интерес к проблеме ПОЛТ и дали толчок для проведения множества рандомизированных исследований. Однако изучение проблемы ПОЛТ при комбинированном лечении НМРЛ было практически прервано после публикации в 1998 метаанализа [35], авторы которого пришли к выводу, что послеоперационная лучевая терапия неэффективна при раке легкого, поскольку ее токсические эффекты превышают терапевтические. Практически сразу мета-анализ ПОЛт 1998 года подвергся критике, так как неудовлетворительные показатели общей выживаемости и относительно низкий уровень локального контроля в группе пациентов с применением ПОЛТ могли быть связаны с использованием в устаревших технологий лучевой терапии и необоснованно больших объемов облучения и высоких СОД [18, 39].

Интерес к ПОЛТ возобновился, когда в ряде публикаций было показано, что использование новых технологий радиотерапии (лучевая терапия, модулируемая по интенсивности (IMRT), лучевая терапия под визуальным контролем (IGRT)) позволяют проводить ПОЛТ без сколь-либо значимых лучевых повреждений жизненно важных органов грудной клетки $[15,16,32]$. Наиболее полное сравнение эффективности ПОЛТ по современным технологиям и по устаревшим методикам проведено в мета - анализе, опубликованном в 2013 году [15]. В исследование вошло 2387 больных НМРЛ. В одном исследовании ПОЛТ проводилась только на гамма-установках, в 6 - на гамма-установках и линейных ускорителях электронов и в четыpex - только на линейных ускорителях электронов. СОД варьировали от 50 до 60Гр. По результатам мета-анализа, для всей группы пациентов проведение ПОЛТ не повышало показателей общей выживаемости (RR 1.02, p=0,84), однако при анализе подгруппы пациентов, облучавшихся на линейных ускорителях, показатели общей выживаемости были достоверно выше (RR 0,76, p=0,02). Помимо этого было установлено, что проведение ПОЛТ позволяет снизить количество локальных рецидивов независимо от аппаратуры, при помощи которой проводилась ЛТ (RR 0,42, $\mathrm{p}=0,0002)$, но наибольшего локального эффекта от проведения ПОЛТ удалось добиться при использовании линейных ускорителей (RR 0,31, p=0.01). 
Табл. 2. Вероятность поражения лимфатических зон средостения (\%) в зависимости от локализации первичной опухоли у 2062 больных НМРЛ [41]

\begin{tabular}{|c|c|c|c|c|c|c|}
\hline \multirow[b]{2}{*}{ Локализация опухоли } & \multicolumn{6}{|c|}{ Лимф. зоны средостения (IASLC) } \\
\hline & $\begin{array}{c}\text { Upper zone } \\
\text { (1,2RL, } \\
\text { 3ap, 4RL) }\end{array}$ & AP zone $(5,6)$ & $\begin{array}{c}\text { Subcarinal } \\
\text { zone (7) }\end{array}$ & $\begin{array}{l}\text { Lower zone } \\
\quad(8,9)\end{array}$ & $\begin{array}{c}\text { Hilar zone } \\
(10,11)\end{array}$ & $\begin{array}{c}\text { Peripheral } \\
\text { zone }(12,13)\end{array}$ \\
\hline Верхняя доля слева & $9 \%$ & $25 \%$ & $5 \%$ & $2 \%$ & $51 \%$ & $2 \%$ \\
\hline Нижняя доля слева & $3 \%$ & $11 \%$ & $15 \%$ & $9 \%$ & $56 \%$ & $2 \%$ \\
\hline Верхняя доля справа & $36 \%$ & $3 \%$ & $7 \%$ & $1 \%$ & $50 \%$ & $3 \%$ \\
\hline Средняя доля & $27 \%$ & $1 \%$ & $21 \%$ & $1 \%$ & $49 \%$ & $5 \%$ \\
\hline Нижняя доля справа & $17 \%$ & $1 \%$ & $27 \%$ & $6 \%$ & $51 \%$ & $4 \%$ \\
\hline Всего & $18 \%$ & $9 \%$ & $14 \%$ & $4 \%$ & $51 \%$ & $3 \%$ \\
\hline
\end{tabular}

Одним из наиболее масштабных исследований в области токсичности ПОЛТ при комбинированном лечении НМРЛ является работа Lally B.E. et al. [29]. В исследование было включено 6148 больных немелкоклеточным раком легкого с $\mathrm{pN} 1$ и $\mathrm{pN} 2$ распространенностью заболевания, радикально прооперированных в 1983-1993 гг. ПОЛТ проводилась у 58\% пациентов. Использование ПОЛТ существенно повышало риск развития заболеваний сердца только в группе пациентов, получивших лечение до 1990 года, которым проводилась лучевая терапия по устаревшей технологии. В исследовании ECOG, опубликованном в 2005 году, было определено, что уровень смертности от сопутствующих заболеваний после проведения ПОЛТ с использованием современных технологий незначительно отличается от уровня смертности от сопутствующих заболеваний в группе хирургического лечения (12.9\% против $10.1 \%$ соответственно) [40].

B ретроспективном исследовании Kepka L. et al. [26] оценили качество жизни и уровень заболеваемости сердечно - сосудистой и легочной систем у радикально прооперированных больных НМРЛ с использованием ПОЛТ по сравнению с пациентами, которым проводилось только хирургическое лечение. Количество смертей не от рака легкого составило 5,3\% в группе ПОЛТ и $5.0 \%$ в группе без ПОЛТ. По качеству жизни отличий найдено не было. Различия функциональных показателей со стороны легочной и сердечно - сосудистой систем между группами пациентов были несущественными (ОФВ был на $1.3 \%$ ниже в группе ПОЛт).

Помимо применения современных технологий лучевой терапии, снизить риск развития лучевых осложнений ПОЛТ возможно путем уменьшения суммарной очаговой дозы, а также сокращением объема облучения. В 2001 году было опубликованы результаты исследования, которое показало существенную зависимость токсичности ПОЛТ при раке легкого от величины суммарной очаговой дозы [31]. Хирургическое лечение и ПОЛТ в СОД 30-68Гр (медиана - 55Гр) получили 202 больных НМРЛ. Контрольная группа подбиралась по факторам риска, характерным для курящего населения США. Четырехлетний риск смертности от интеркуррентных заболеваний составил в основной группе 13,5\%, в контрольной - 10\% $(\mathrm{p}=0.06)$, однако для больных с СОД менее 54 Гр он составил всего $2 \%$, а при СОД более 54Гр - 17\%.

По результатам проведенного нами исследования [6, 8] ПОЛТ с РОД-ЗГр до СОД-36-39Гр (EQD2=43,2-46,8Гр, / =3) при комбинированном лечении больных НМРЛ позволяет статистически значимо повысить общую и безрецидивную 5-летнюю выживаемость при метастатическом поражении регионарных лимфатических узлов корня легкого (pN1: 46,9\% vs 39,6\%, 53,9\% vs 19,1\%, соответственно) и медиастинальных лимфатических узлов (pN2: $41,8 \%$ vs $6,5 \%, 40,1 \%$ vs $8,6 \%$, соответственно), а так же фактически в 4 раза снижает число локорегионарных рецидивов (с 31,6\% до 7,6\%, p=0,04) при IА-ІІІВ стадии заболевания по сравнению с хирургическим лечением больных НМРЛ и доводит уровень 5-летней выживаемости без локорегионарного рецидива до 85-90\%. Однако, в группе радикально оперированных больных $\mathrm{pN} 0$, равно как и при IA-IB стадиях, наблюдается хотя и незначительное, но уменьшение общей выживаемости (62,1\% vs 68,4\% и $67,4 \%$ vs $69,3 \%$, соответственно). Очевидно, что у части больных этих групп мишени для послеоперационной лучевой терапии нет, и у них практически в чистом виде регистрируется повреждающей эффект ПОЛТ, который при более поздних стадиях кратно перекрывается ее терапевтическим эффектом. Увеличение продолжительности жизни больных с более поздними стадиями заболевания, которым проводилась ПОЛТ, связано с улучшением локорегионарного контроля заболевания, и, возможно, как следствие этого, уменьшением частоты каскадного метастазирования из зон местного рецидива.

Важным аспектом при проведении ПОЛТ является выбор оптимального объема облучения, при котором терапевтический эффект и токсичность данной методики лечения будут находиться в оптимальном соотношении. В последнее время во многих клиниках мира проявляется повышенный интерес к поиску предикторов регионарного метастазирования НМРЛ [44], а так же к поиску закономерностей поражения лимфатических зон средостения в зависимости от локализации первичной опухоли легкого. В наиболее крупном исследовании Wang Y. et al. 
Табл. 3. Частота метастатического пораженных лимфатических зон средостения в зависимости от расположения первичной опухоли [12]

\begin{tabular}{|c|c|c|c|c|c|c|c|c|}
\hline \multirow{2}{*}{ Локализация опухоли } & \multicolumn{8}{|c|}{ Частота поражения лимфатических зон средостения (по IASLC) } \\
\hline & $2 \mathrm{~L}$ & $2 \mathrm{R}$ & $4 \mathrm{~L}$ & $4 \mathrm{R}$ & 5 и 6 & 7 & 8 & 9 \\
\hline Вдлл & $10 \%$ & $7 \%$ & $16 \%$ & $8 \%$ & $17 \%$ & $12 \%$ & $2 \%$ & $0 \%$ \\
\hline Ндлл & $0 \%$ & $4 \%$ & $18 \%$ & $6 \%$ & $14 \%$ & $16 \%$ & $7 \%$ & $12 \%$ \\
\hline вдпл сдпл & $4 \%$ & $19 \%$ & $5 \%$ & $23 \%$ & - & $14 \%$ & $0 \%$ & $0 \%$ \\
\hline НДПл & $6 \%$ & $8 \%$ & $10 \%$; & $12 \%$ & - & $17 \%$ & $11 \%$ & $3 \%$ \\
\hline
\end{tabular}

Примечание: ВДПЛ- верхняя доля правого легкого; СдПЛ- средняя доля правого легкого; НДПЛ- нижняя доля правого легкого; ВДЛЛ- верхняя доля левого легкого; НДЛЛ- нижняя доля левого легкого

[41] рассматривались закономерности поражения различных зон лимфатических узлов средостения по IASLC [21] от локализации первичной опухоли у оперированных больных НМРЛ (табл. 2).

По результатам данной работы при локализации рака легкого в верхней доле слева наиболее часто поражаются субаортальные (5 зона) и парааортальные (6 зона) лимфатические узлы. При левосторонней нижнедолевой локализации опухоли такими зонами являются бифуркационные лимфатические узлы (7 зона). При поражении верхней, средней и нижней доли правого легкого верхние и нижние паратрахеальные (2R, 2L, 4R, 4L зоны), преваскулярные (За зона) и ретротрахеальные (3p зона) лимфатические узлы являлись наиболее частыми локализациями регионарных метастазов. Для среднедолевой и нижнедолевой правосторонней локализации опухоли легкого дополнительной зоной с высокой частотой метастазирования являлись бифуркационные лимфатические узлы (7 зона). Только при локализации опухоли в нижних долях легких наблюдались поражения преэзофагеальных лимфатических узлов (8 зона) и лимфатических узлов легочной связки (9 зона).

Близкие результаты по зависимости частоты поражения различных лимфатических зон средостения от локализации первичной опухоли легкого приведены в монографии П.К. Яблонского и А. С. Петрова [12] (табл. 3).

По их данным наиболее часто поражаются ипсилатеральные паратрахеальные (2 и 4 группы) и бифуркационные лимфатические узлы (7 группа) при различных локализациях опухоли, а так же субаортальные и парааортальные лимфатические узлы при расположении первичного очага в левом легком. Кроме того авторы отмечают, что локализация рака легкого в верхней доле практически исключает метастатическое поражение параэзофагиальных лимфатических узлов и лимфатических узлов легочной связки.

Таким образом, исключение из облучаемого объема ПОЛТ 8 и 9 лимфатических зон средостения при верхнедолевой и среднедолевой локализации опухоли и 9 зоны при локализации рака легкого в нижних долях легкого не приведет к значительному повышению количества регионарных рецидивов. Позволит значительно снизить токсичность лучевого лечения, повысит как качество, так и продолжительность жизни больных НМРЛ, которым показано проведение ПОЛТ.

В итоге, принимая во внимание все сказанное выше, можно утверждать, что современные технологии послеоперационной лучевой терапии (КТ-топометрия, трехмерное дозиметрическое планирование лучевой терапии, IMRT, IGRT), а так же определение оптимального объема облучения в соответствии с риском поражения различных групп регионарных лимфатических узлов при различной локализации рака легкого и снижение СОД до уровня 4450Гр, позволяют уменьшить лучевые повреждения критических органов и повысить уровень локорегионарного контроля и выживаемость больных при комбинированном лечении НМРЛ с метастазами в регионарные лимфатические узлы.

\section{Литература • References}

1. Вальков М.Ю., Скрипач Ю. В., Соловьева Е. П. с соавт. Методы лечения и исходы при местно-распространенном раке легкого ІІІ стадии: популяционный анализ. // Вестник РНЦРР. - 2014. - №9. - стр. 9.

2. Миллер С. В., Тузиков С. А., Завьялов А. А. с соавт. Анализ осложнений комбинированного лечения немелкоклеточного рака легкого. // Сибирский онкологический журнал. - 2007. - Т. 4. - С. 50-56.

3. Михина 3.П., Горбунова В.А., Ткачев С. И. с соавт. Современная химиолучевая терапия больных с немелкоклеточным раком легкого. // Медицинская радиология и радиационная безопасность. - 2012. - Т. 57. - №2. - С. $26-30$.

4. Паршин В.Д., Белов Ю. В., Выжгина М. А. Хирургия злокачественных опухолей легкого у больных старше 70 лет. // Хирургия. Журнал им. Н. И. Пирогова. - 2010. - №10. - С. 11-16.

5. Петерсон Б. Е. Рак легкого. // М. Медицина. - 1971. - С. 24-26. 
6. Солодкий В.А., Харченко В.П., Чхиквадзе В.Д. и др. Результаты хирургического и комбинированного лечения немелкоклеточного рака легкого с послеоперационной лучевой терапией в режиме гипофракционирования. сообщение II. Безрецидивная выживаемость и выживаемость без локорегионарного рецидива. // Вопросы онкологии. - 2016. - Т. 62. - №1. - С. $72-78$.

7. Трахтенберг А. Х., Колбанов К. И., Вурсол Д. А. Расширенные и комбинированные операции при местно-распространенном немелкоклеточном раке легкого. // Российский онкологический журнал. - 2007. - №2 2. - С. 9-14.

8. Троценко С. Д., Солодкий В. А., Сотников В. М. и др. Результаты хирургического и комбинированного лечения немелкоклеточного рака легкого с послеоперационной лучевой терапией в режиме гипофракционирования. Общая и болезньспецифичная выживаемость. // Вопросы онкологии. - 2015. - Т. 61. - №1. - С. 71-76.

9. Харченко В.П., Волохов В.Э. Комбинированное лечение больных раком легкого. // Материалы научной работы по онкологии. 1966. - C. 38-42.

10. Харченко В.П., Кузьмин И. В. Рак легкого. Руководство для врачей. // М.: Медицина. - 1994. - стр. 92.

11. Харченко В.П., Чхиквадзе В.Д., Паньшин Г. А. Комбинированое и хирургическое лечение больных раком легкого. // Вестник Московского Онкологического Общества. - 2009. - № 9. - стр. 5.

12. Яблонский П.К., Петров А.С. Видеомедиастиноскопия и другие методы N-стадирования в хирургии рака легкого // ГеотарМедиа. - 2015. - С. 26-28.

13. Arriagada R., Auperin A., Burdett S. et al: Adjuvant chemotherapy with or without postoperative radiotherapy in operable non-smallcell lung cancer: two meta-analyses of individual patient data. // Lancet. - 2010. - V. 375. - P. 1267-1277.

14. Astudillo J., Conill C. Role of postoperative radiation therapy in stage Illa non-small cell lung cancer. // Ann Thorac Surg. - 1990. V. 50. - P. 618-623.

15. Billiet C., Decaluwe H., Peeters S. et al. Modern post-operative radiotherapy for stage III non-small cell lung cancer may improve local control and survival: A meta-analysis. // Radiother. Oncol. - 2013. - V. 110. - №1. - P. 3-8.

16. Billiet C., Gouw Z., Defraene G. et al. Postoperative radiotherapy in resected ypN2 stage III-N2 non-small cell lung cancer: can modern conformal radiotherapy compensate for the poor outcome? // Annals of Oncology. - 2014. - V25. - № 4. - P. 417-425.

17. Chung C. K., Stryker J. A., O"Neill M. Jr. et al. Evaluation of adjuvant postoperative radiotherapy for lung cancer. // Int J Radiat Oncol Biol Phys. - 1982. - T. 8. - P. 1877-1880.

18. Corso C. D., Rutter C. E., Wilson L. D. et al. Re-evaluation of the Role of Cancer Using the National Cancer Database. // J. Thorac. Oncol. - 2015. - V. 10. - P. 148-155.

19. Douillard J.Y., Rosell R., De Lena M. et al. Adjuvant vinorelbine plus cisplatin versus observation in patients with completely resected stage IB-IIIA non-small-cell lung cancer (Adjuvant Navelbine International Trialist Association [ANITA]): a randomised controlled trial. // Lancet Oncol. - 2006. - V. 7. - P. 719-727.

20. Fan C, Gao S, Hui Z, Liang J, Lv J, Wang X et al (2013) Risk factors for locoregional recurrence in patients with resected N1 non-small cell lung cancer: a retrospective study to identify patterns of failure and implications for adjuvant radiotherapy. // Radiat Oncol. V. 8. - P. 286

21. Goldstraw P., Crowley J., Chansky K. et al. The IASLC Lung Cancer Staging Project: proposals for the revision of the TNM stage groupings in the forthcoming (seventh) edition of the TNM classification of malignant tumours // J. Thorac. Oncol. - 2007. - V. 2. P. 706-714.

22. Ichinose Y., Kato H., Koike T. et al. Overall survival and local recurrence of 406 completely resected stage Illa-N2 non-small cell lung cancer patients: Questionnaire survey of the Japan Clinical Oncology Group to plan for clinical trials. // Lung Cancer. - 2001. - V. 34. P. 29-36.

23. International Adjuvant Lung Cancer Trial Collaborative Group. Arriagada R., Bergman B., Dunant A. et al. Cisplatin-based adjuvant chemotherapy in patients with completely resected non-small-cell lung cancer. // N Engl J Med. - 2004. - V. 350. - P. 351-360.

24. Jemal A., Bray F., Center M. M. et al. Global cancer statistics. CA Cancer J Clin. - 2011. -V. 61. -P. 69-90.

25. Kelsey C. R., Marks L. B., Hollis D. et al. Local recurrence after surgery for early stage lung cancer: An 11-year experience with 975 patients. // Cancer. - 2000. - V. 115. - P. 5218-5227.

26. Kepka L., Bujko K., Orlowski T. M. et al. Cardiopulmonary morbidity and quality of life in non-small cell lung cancer patients treated with or without postoperative radiotherapy. // Radiother. Oncol. - 2011. - V. 98. - №2. - P. 238-243.

27. Kirsh M. M., Sloan H. Mediastinal metastases in bronchogenic carcinoma: Influence of postoperative irradiation, cell type and ocation. // Ann Thorac. - 1982. - T. 33. - P. 459-463.

28. Kolodziejczyk M., Bujko K., Michalski W., Kepka L. Incidence of isolated nodal failure in non-small cell lung cancer patients included in a prospective study of the value of PET - CT. // Radiotherapy and Oncology. - 2012. - V. 104 - № 1. - P. 58-61. 
29. Lally B. E., Detterbeck F. C., Geiger A. M. et al. The risk of death from heart disease in patients with non-small cell lung cancer who receive postoperative radiotherapy: analysis of the Surveillance, Epidemiology, and End Results database. // Cancer. - 2007. V. 110. - № 4. - P. 911-917.

30. Landreneau J. P., Schuchert M. J., Weyant R. et al. Anatomic segmentectomy and brachytherapy mesh implantation for clinical stage I non-small cell lung cancer (NSCLC). // Surgery. - 2014. - V. 155. - P. 340-346.

31. Machtay M., Lee J.H., Shrager J. B., Kaiser L. R., Glatstein E. Risk of Death From Intercurrent Disease Is Not Excessively Increased by Modern Postoperative Radiotherapy for High-Risk Resected Non - Small-Cell Lung Carcinoma. // Journal of Clinical Oncology. 2001. - V. 19. - № 19. - P. 3912-3917.

32. Patela S. H., Mab Y., Wernickea A. G. et al. Evidence supporting contemporary post-operative radiation therapy (PORT) using linear accelerators in N2 lung cancer. // Lung Cancer. - 2014. - V. 84. - P. 156-160.

33. Paterson R., Russell M. H. Clinical trials in malignant disease. Part-IV-Lung Cancer. Value of post-operative radiotherapy. // Clinical radiology. - 1962. - P. 141-144.

34. Pignon J.P., Tribodet H., Scagliotti G. V. et al. Lung adjuvant cisplatin evaluation: a pooled analysis by the LACE collaborative group. // J Clin Oncol. - 2008. - V. 26. - P. 3552-3559.

35. PORT Meta-analysis Trialists Group. Postoperative radiotherapy in non-small-cell lung cancer: Systematic review and meta-analysis of individual patient data from nine randomised controlled trials. // Lancet. - 1998. - V. 352. - P. 257-263.

36. Robinson C. G., Patel A. P., Bradley J. D. et al. Postoperative Radiotherapy for Pathologic N2 Non - Small-Cell Lung Cancer Treated With Adjuvant Chemotherapy: A Review of the National Cancer Data Base. // J. Clin. Oncol. - 2015. - V. 34. - P. 2-8.

37. Sawyer T. E., Bonner J. A., Gould P. M. et al. Effectiveness of postoperative irradiation in stage IIIA non-small cell lung cancer according to regression tree analyses of recurrence risks. // Ann Thorac Surg. - 1997. - T. 64. - P. 1402-1408.

38. Su S., Scott W. J., Allen M. S. et al. Patterns of survival and recurrence after surgical treatment of early stage non - small cell lung carcinoma in the ACOSOG Z0030 (ALLIANCE) trial. // J. Thorac Cardiovasc. Surg. - 2014. - V. 147. - P. 747-753.

39. Thames H.D. Postoperative radiotherapy of non-small cell lung cancer: a flow in the PORT meta-analysis. // Progress in Radiotherapy VII. - Bologna. - 2002. - P. 9-16.

40. Wakelee H. A., Stephenson P., Keller S. M. et al. Post-operative radiotherapy or chemoradiotherapy following resection of stages II and IIIA non-small cell lung cancer does not increase the expected risk of death from intercurrent disease in Eastern Cooperative Oncology Group trial E3590. // Lung Cancer. - 2005. - V. 48. - P. 389-397.

41. Wang Y., Li B., Huang W. et al. Pattern of lymph node metastases and its implication in radiotherapeutic clinical target volume in patients with non-small-cell lung cancer: a study of 2062 cases. // Br. J. Radiol. - 2015. - V. 88. - P. 1-8

42. Warren M., Webster G., Ryder D. et al. An isotoxic planning comparison study for stage II-III non-small cell lung cancer: is intensitymodulated radiotherapy the answer? // Clinical Oncology. - 2014. - V. 26. - № 8. - P. 461-467.

43. Winton T., Livingston R., Johnson D. et al. Vinorelbine plus cisplatin vs. observation in resected non-small-cell lung cancer. // N. Engl. J. Med. - 2005. - V. 352. - №25. - P. 2589-2597.

44. Zhang Y., Sun Y., Xiang J. et al. A prediction model for N2 disease in T1 non - small cell lung cancer. // J. Thorac Cardiovasc. Surg. 2012. - V. 144. - P. 1360-1364.

45. Zhang Y., Sun Y., Xiang J. et al. A clinicopathologic prediction model for postoperative recurrence in stage la non - small cell lung cancer. // J. Thorac Cardiovasc. Surg. - 2014. - V. 195. - №2. - P. 1-7. 